Annales Geophysicae (2003) 21:75-87 C) European Geosciences Union 2003

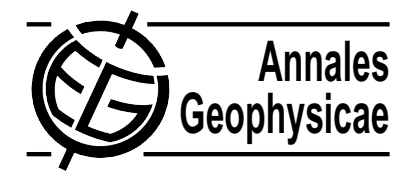

\title{
The Mediterranean Moored Multi-sensor Array (M3A): system development and initial results
}

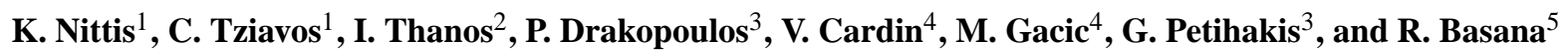 \\ ${ }^{1}$ National Centre for Marine Research, Institute of Oceanography, A. Kosmas Hellinikon, 16604, Athens, Greece \\ ${ }^{2}$ Marine Technology Development Company (MARTEDEC) SA, Athens, Greece \\ ${ }^{3}$ Institute of Marine Biology of Crete, Heraklion, Greece \\ ${ }^{4}$ Istituto Nazionale di Oceanografia e di Geofisica Sperimentale, Trieste, Italy \\ ${ }^{5}$ Tecnomare SA, Venice, Italy
}

Received: 14 June 2001 - Revised: 14 January 2002 - Accepted: 23 January 2002

\begin{abstract}
Operational forecasting of ocean circulation and marine ecosystem fluctuations requires multi-parametric real-time measurements of physical and biochemical properties. The architecture of a system that is able to provide such measurements from the upper-thermocline layers of the Mediterranean Sea is described here. The system was developed for the needs of the Mediterranean Forecasting System and incorporates state-of-the-art sensors for optical and chemical measurements in the upper $100 \mathrm{~m}$ and physical measurements down to $500 \mathrm{~m}$. Independent moorings that communicate via hydro-acoustic modems are hosting the sensors. The satellite data transfer and the large autonomy allow for the operation of the system in any open-ocean site. The system has been in pre-operational use in the Cre$\tan$ Sea since January 2000. The results of this pilot phase indicate that multi-parametric real-time observations with the M3A system are feasible, if a consistent maintenance and recalibration program is followed. The main limitations of the present configuration of $\mathrm{M} 3 \mathrm{~A}$ are related: (a) to bio-fouling that primarily affects the turbidity and secondarily affects the other optical sensors, and (b) to the limited throughput of the currently used satellite communication system.
\end{abstract}

Key words. Atmospheric composition and structure (instruments and techniques.) Oceanography: general (ocean prediction) Oceanography: physical (upper ocean process)

\section{Introduction}

The fast evolving technology of oceanographic in situ and remote sensing instruments (Tziavos and Flemming, 1999) and the advancements in the field of numerical modelling and data assimilation during the last decade have allowed for the development of the first applications of Operational Oceanography. These applications were also boosted by the increasing demand for reliable observations and forecasts

Correspondence to: K. Nittis (knittis@ncmr.gr) of marine environmental conditions (Fisher and Flemming, 1999). The importance of Operational Oceanography was recognized by the international scientific community and the Global Ocean Observing System (GOOS) undertook the coordination of scientific efforts to develop regional or global observing and forecasting systems (IOC 1996).

In the framework of EuroGOOS, which is the European component of GOOS (Woods et al., 1996), the Mediterranean Forecasting System (MFS) is a multinational effort to develop an integrated operational monitoring and forecasting system for the Mediterranean Sea (Pinardi and Flemming, 1998). During the pilot phase of the project (1998-2001), the goal was to demonstrate the feasibility of weekly forecasts of basin-scale hydrological and general circulation properties with assimilation of near real-time data. The observational basis of the system has 3 main components: (a) XBT measurements from Volunteer Observing Ships (VOS), (b) multidisciplinary measurements from a network of fixed buoys and (c) satellite observations of Sea Surface Temperature (SST), Sea Surface Height (SSH) and Ocean Colour. The development of the second observing component of MFS, the so-called Mediterranean Moored Multi-sensor Array (M3A), is described here.

The prototype M3A system was designed to form the base of a permanent network of moored stations for continuous monitoring of open-ocean conditions in the Mediterranean Sea. This effort was based on the experience of the well-known Tropical Atmosphere-Ocean (TAO) array of the Equatorial Pacific (McPhaden et al., 1998) and similar developments on multi-parametric measurements at the Bermuda Test-Bed Mooring (Dickey et al., 1998).

The TAO array is the main observing system of the Tropical Ocean-Global Atmosphere (TOGA) program that is focused on the interannual variability of the coupled oceanatmosphere system associated with the El Niño Southern Oscillation (ENSO). This program led to fundamental progress in the understanding of the processes responsible for ENSO and the development of coupled models for its prediction of 
Table 1. List of parameters measured by the M3A system

\begin{tabular}{|c|c|c|c|c|c|c|c|c|c|}
\hline \multicolumn{10}{|c|}{ Measurements in the water column } \\
\hline & -1 & -40 & -65 & -90 & -115 & -150 & -250 & -350 & -500 \\
\hline Temperature & $\bullet$ & $\bullet$ & $\bullet$ & $\bullet$ & $\bullet$ & $\bullet$ & • & • & $\bullet$ \\
\hline Salinity & $\bullet$ & $\bullet$ & $\bullet$ & $\bullet$ & $\bullet$ & $\bullet$ & $\bullet$ & $\bullet$ & $\bullet$ \\
\hline Light Attenuation & $\bullet$ & $\bullet$ & $\bullet$ & $\bullet$ & $\bullet$ & & & & \\
\hline Dissolved Oxygen & $\bullet$ & $\bullet$ & $\bullet$ & $\bullet$ & $\bullet$ & & & & \\
\hline Chlorophyll-a & $\bullet$ & $\bullet$ & $\bullet$ & $\bullet$ & • & & & & \\
\hline PAR & & $\bullet$ & $\bullet$ & $\bullet$ & $\bullet$ & & & & \\
\hline Nutrients (Nitrate) & & $\bullet$ & & & & & & & \\
\hline Current speed/direction & \multicolumn{9}{|c|}{ 0-500 m profile } \\
\hline \multicolumn{10}{|c|}{ Measurements at air-sea interface } \\
\hline Air & \multirow{2}{*}{\multicolumn{2}{|c|}{$\begin{array}{l}\text { Relative } \\
\text { Humidity }\end{array}$}} & \multirow{2}{*}{\multicolumn{2}{|c|}{$\begin{array}{l}\text { Atmospheric } \\
\text { Pressure }\end{array}$}} & \multirow{2}{*}{\multicolumn{2}{|c|}{$\begin{array}{l}\text { Wind speed and } \\
\text { direction }\end{array}$}} & \multirow{2}{*}{\multicolumn{3}{|c|}{$\begin{array}{l}\text { Wave } \\
\text { parameters }\end{array}$}} \\
\hline Temperature & & & & & & & & & \\
\hline
\end{tabular}

(Philander, 1999). Today, the TAO array is based on approximately 70 ATLAS and TRITON buoys that have similar measuring capabilities and mooring designs. They are developed to provide real-time measurements of temperature and salinity in the upper $500 \mathrm{~m}$ of the ocean $(750 \mathrm{~m}$ for the TRITON buoys), as well as meteorological parameters (wind, air temperature, atmospheric pressure, humidity, precipitation) at the surface. Few sites are equipped with Acoustic Doppler Current Profilers (ADCP) that provide current data in delayed mode whenever the moorings are recovered. The PIRATA array in the tropical Atlantic uses the same type of buoys and monitoring strategy to study ocean-atmosphere interaction relevant to regional climate variability.

The main goal of the Bermuda Test-Bed Mooring (BTM) program was to provide to the scientific community a platform for developing, testing and calibrating instruments for long-term monitoring (Dickey, 1995). The system is a fixed mooring with a surface buoy equipped with instruments for meteorological and spectral radiometric measurements, while various instruments for physical and biochemical measurements at subsurface and deeper layers are attached on the mooring wire. Special attention is given to the optical properties and several new instruments have been developed. Since its deployment in 1994 the system has provided valuable information on episodic and periodic processes at different time scales (McNeil et al., 1999). Although the BTM was not initially designed as a real-time monitoring system, it has demonstrated the feasibility of operational, long-term, physical and biochemical measurements in the ocean.

A similar design is followed by the HALE-ALOHA (Hawaii Air-sea Logging Experiment, A Long-term Oligotrophic Habitat Assessment) station that has collected physical and biochemical data since 1997. The system is part of the HOT (Hawaii Ocean Time-series) program, which is a long-term observation experiment based on both ship and mooring measurements (Chiswell and Lucas, 1990). The overall goal of the program is to study the north Pacific subtropical gyre, by understanding the seasonal and interannual variability of water masses and bio-chemical characteristics in the area and relate them to gyre fluctuations. Apart from the HALE-ALOHA system, the fixed mooring network includes two inverted echo sounder moorings and a sequencing sediment trap mooring.

A different approach for continuous multidisciplinary measurements in the water column is the use of profiling vehicles equipped with sensors (Provost et al., 1996). The advantage of such systems, usually called yoyos, is their relatively low cost, since a single-set of instruments is required for all measurements. They are capable of providing measurements with very high vertical resolution, compared to conventional moorings where instruments are placed at preselected depths. Furthermore, they can minimize bio-fouling problems since the vehicle can park in a low-fouling zone. Their deployment procedure is difficult due to their complicated mooring requirements. Up todate, these systems have not provided long time series, but the ongoing research is expected to further improve their characteristics and develop reliable solutions in the near future.

Underwater and satellite communication technologies have been rapidly developing during the last few years. The DOMEST project is developing an open network structure for deep-sea deployments near the Canary Islands (Meinecke et al., 2000). The system consists of a subsurface platform, as well as intermediate and deep ocean units equipped with sediment traps, CTD instruments, optical sensors, current meters and ADCP. Their communication technology is based 
Table 2. Type and accuracy of sensors used for the oceanographic measurements of the M3A system

\begin{tabular}{|c|c|c|c|c|}
\hline Parameter & Instrument type & Sensor Range & Sensor accuracy & Units \\
\hline Conductivity (1.5 m) & Aanderaa 3211 & $0-7.5$ & 0.015 & $\mathrm{~S} / \mathrm{m}$ \\
\hline Temperature $(1.5 \mathrm{~m})$ & Aanderaa 3211 & $-5-35$ & 0.1 & Celsius \\
\hline D. Oxygen $(1.5 \mathrm{~m})$ & Aanderaa 3713 & $0-15$ & 0.4 & $\mathrm{ml} / 1$ \\
\hline Light attenuation (1.5 m) & Wetlabs C-star transmissometer & $0-100$ & 0.025 & $\%$ \\
\hline Chlorophyll (1.5 m) & Wetlabs WETStar fluorometer & $0.03-75$ & 0.03 & $\mu \mathrm{g} / 1$ \\
\hline Conductivity (40-115 m) & SBE-16 SEACAT & $0-7$ & 0.001 & $\mathrm{~S} / \mathrm{m}$ \\
\hline Temperature (40-115 m) & SBE-16 SEACAT & $-5-35$ & 0.01 & Celcius \\
\hline Pressure (40-115 m) & SBE-16 SEACAT & $0-200$ & 0.2 & dbar \\
\hline D. Oxygen $(40-115 \mathrm{~m})$ & SBE 23 DO sensor & $0-15$ & 0.1 & $\mathrm{ml} / 1$ \\
\hline Light attenuation (40-115 m) & Wetlabs C-star transmissometer & $0-100$ & 0.025 & $\%$ \\
\hline Chlorophyll (40-115 m) & Wetlabs WETStar fluorometer & $0-75$ & 0.03 & $\mu \mathrm{g} / 1$ \\
\hline PAR (40-115 m) & LI-COR 193SA & $0-1000$ & 1. & microeinsteins $\mathrm{s}^{-1} \mathrm{~m}^{-2}$ \\
\hline Nitrate $(65 \mathrm{~m})$ & WS Ocean NAS2-EN & $0-5$ & 0.1 & $\mu \mathrm{mol} / 1$ \\
\hline Conductivity (150-500 m) & SBE 37 MICROCAT & $0-7$ & 0.0003 & $\mathrm{~S} / \mathrm{m}$ \\
\hline Temperature (150-500 m) & SBE 37 MICROCAT & $-5-35$ & 0.002 & Celcius \\
\hline Pressure (150-500 m) & SBE 37 MICROCAT & $0-600$ & 0.6 & dbar \\
\hline Current (0-500 m) & RDI Longranger $75 \mathrm{kHz}$ & $0-5$ & 0.05 & $\mathrm{~m} / \mathrm{s}$ \\
\hline
\end{tabular}

on underwater acoustic modems and satellite transmission through the Orbcomm system, which is a Low Earth Orbit (LEO) satellite platform. Another category of deep-sea observatories is using existing submarine telephone cables to transmit data. The advantage of this approach, apart from the high throughput for data transmission, is the ability to power the station on a permanent basis using the same cable (Butler et al., 1992). The Hawaii-2 Observatory (H2O) is using such a cable to operate a deep-sea $(5000 \mathrm{~m})$ station equipped with seismometer, geophone and hydrophone instruments. In the future, the station will be equipped with instruments for physical, biological and tsunami studies.

The development of a modular upper ocean observing system and the initial results from its first year of operation are presented here. In Sect. 2, the M3A system architecture and its components are described. Data transmission and management strategies are also presented in this section. The operation during the pilot phase of MFS and the various problems that were encountered are described in Sect. 3. In Sect. 4, the quality of the M3A data collected during the pilot phase is discussed and selected time series are briefly described. The main results and conclusions are summarized in Sect. 5 and some comments on future perspectives are given.

\section{The M3A system}

The M3A design followed the requirements of the MFS science plan (Pinardi and Flemming, 1998), according to which the system should measure physical properties of the upper $500 \mathrm{~m}$ of the ocean, biochemical variables at the upper $100 \mathrm{~m}$ and air-sea interaction variables at the surface (Table 1). In this way, the system should be able to monitor the upper thermocline variability of the general circulation and biochemical processes in the euphotic zone. Furthermore, the system should be able to transmit the collected data in real time to an operational centre where data should be pre-processed and delivered in Near Real Time (NRT) to the MFS partners. Finally, the system should be able to operate in open-sea conditions, and be moored at depths above $1000 \mathrm{~m}$. These requirements defined the technical characteristics and the design of the M3A system.

In the pilot phase of MFS, the M3A data were used for calibration/validation of ecological models developed for the Mediterranean Sea, as well as for the development of appropriate data assimilation techniques. Hence, these data were not used in real time by other project components. Their NRT delivery was mainly a demonstration that coordinated NRT data collection from the different MFS observational components is feasible during a Targeted Operational Period (TOP) of six months. During the next phase of MFS, addi- 


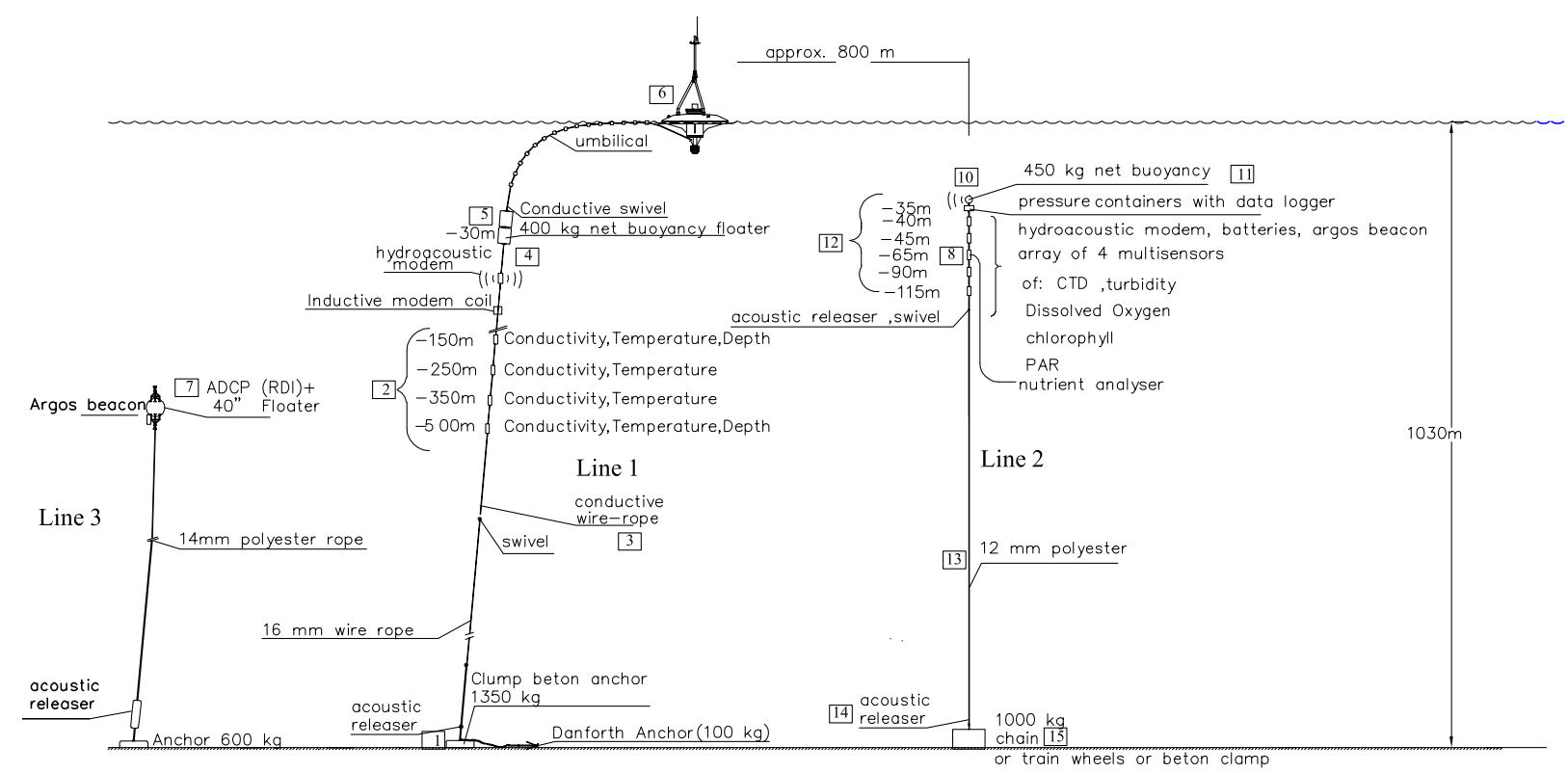

Fig. 1. Design of the M3A system.

tional M3A systems will be developed for other areas of the Mediterranean Sea and their data will be assimilated into the operational basin-scale forecasting system.

\subsection{Configuration and sensor suites}

The M3A system is composed of three independent mooring lines (Fig. 1), one central (line 1) and two peripherals (lines 2 and 3). This configuration allows for separate and thus, easier maintenance of lines 2 and 3 that have a high maintenance frequency, (every 2-3 months) and can be handled by a medium size vessel. In contrast, line 1 has a lower maintenance frequency (once a year), but requires the presence of a larger research vessel. At the same time, this modular configuration guarantees the expandability of the system that can be enriched in the future with additional instruments on separate moorings with acoustic data transfer between them.

Line 1 is the central mooring that hosts a surface buoy with the code name "Medousa" (Thanos et al., 1997) and the sensors for physical parameters at deep layers (below $100 \mathrm{~m}$ ). Four CTDs (element 2 in Fig. 1) are used at 150, $250,350,500 \mathrm{~m}$ to measure temperature, conductivity and pressure (Table 2). Data are transferred to the surface by a $600 \mathrm{~m}$ inductive-modem cable. This cable (element 3 in Fig. 1) is connected to the subsurface umbilical by a conductive swivel at $30 \mathrm{~m}$. The swivel (from Focal Technologies) allows for the free rotation of the surface buoy, but at the same time it conducts the signal of the deep sensors (element 4). At the same depth, the hydroacoustic modem (Orca-MATS-12, element 5) receives the data of line 2 and transfers the data to the surface buoy though the umbilical. A pair of acoustic releasers of $4500 \mathrm{~kg}$ capacity is placed above the anchoring system to allow for easy recovery of the whole line.
The surface buoy is hosting the surface ( $1.5 \mathrm{~m}$ depth) sensors suite (temperature, conductivity, turbidity, dissolved oxygen and chlorophyll-a), the meteorological and wave sensors (wind speed and direction, air temperature, atmospheric pressure, humidity, wave height and direction), plus the data storage and transmission system. The customized cage of the oceanographic sensors allows for an easy detachment from the buoy for cleaning and repair. Those sensors have the same maintenance requirements as those of line 2 .

Line 2 is hosting four CTD instruments at 40, 65, 90 and $115 \mathrm{~m}$, and a nutrient (nitrate) analyser at $45 \mathrm{~m}$ depth (Fig. 2). Apart from temperature, conductivity and pressure sensors, each CTD probe is equipped with a light attenuation sensor (transmissometer), a chlorophyll-a sensor (fluorometer), a PAR (photosynthetically active radiation) sensor and a dissolved oxygen sensor. The four devices are networked with an RS-485 interface, while an RS-232 to RS-485 converter allows for the communication with the nutrient analyser. A pressure container at $35 \mathrm{~m}$ depth (element 11) is hosting the computer (code name "Nireus") that controls line 2, stores the data and transmits the data to mooring line 1 through the acoustic modem that is attached to the flotation device (element 10) above the pressure container. For communication between the two modems, a data rate of $20 \mathrm{bit} / \mathrm{s}$ and the CHIRP modulation, recommended for a horizontal transmission, were chosen. Line 2 is also equipped with two releasers at 125 and $1000 \mathrm{~m}$ and an Argos beacon (Orca-BASM500) that transmits the mooring position if the flotation device comes to surface by accident.

The same type of beacon is used on the flotation device of line 3 that hosts the upward looking ADCP. This device is at $500 \mathrm{~m}$ depth, measuring the current profile from that depth up to the surface. It was anchored at about $1 \mathrm{~nm}$ away for line 1 . 


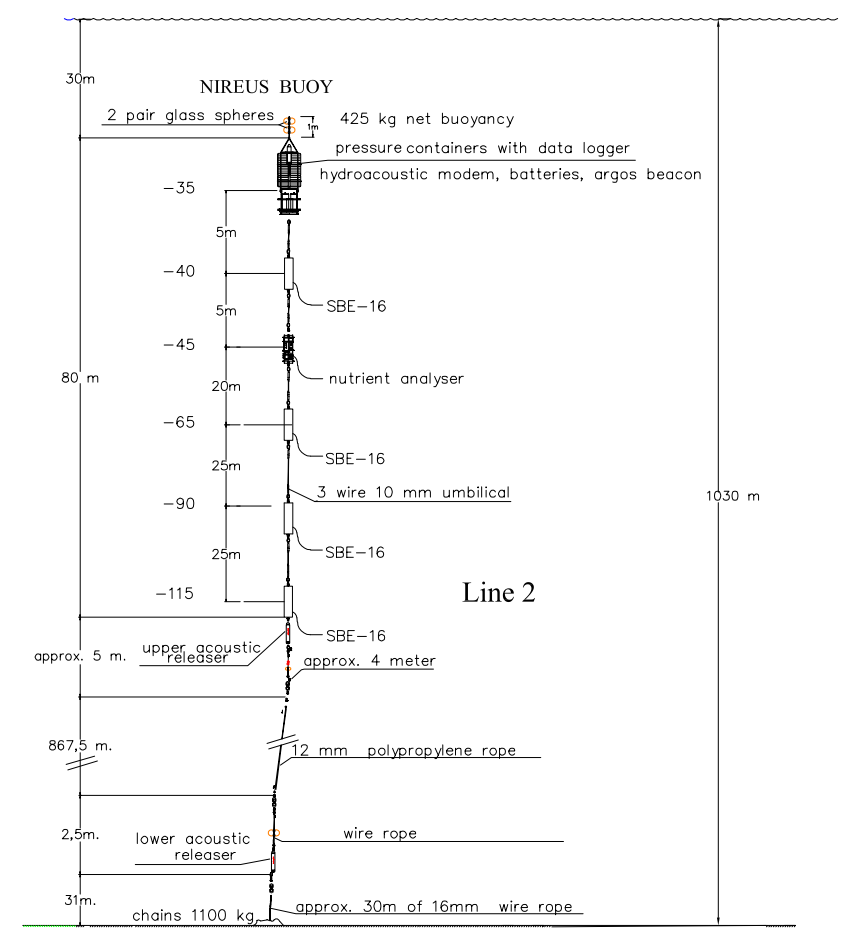

Fig. 2. Details of line 2 of M3A.

This system does not include real-time data transfer to the surface buoy, since the large volume of ADCP data does not allow for their transmission through a satellite (at least with the current system capabilities). With a sampling interval of $30 \mathrm{~min}$, the autonomy of the system is approximately 6 months, which is the maintenance interval for mooring line 3. An acoustic releaser at $1000 \mathrm{~m}$ allows for the easy recovery and re-deployment of the system.

\subsection{Measurement sequencing and data flow}

Two Intel-PCs are used for the acquisition of data and control of the system: the $80486 \mathrm{PC}$ of the surface buoy and the CMF 8680 of the "Nireus" logger in line 2. The CPUs of both systems have been programmed to start operation every $3 \mathrm{~h}$. The first step is the acquisition of line 2 data from the "Nireus" logger and the transmission to the surface buoy through the acoustic modem. The second step is the data acquisition from the deep instruments of line 1, using the inductive modem controller. The third step is the acquisition of data from the sensors of the surface buoy. The whole data acquisition procedure has a duration of $40 \mathrm{~min}$. When this procedure is completed, data are encoded and transmitted to the MFS buoy operational center (Fig. 3).

For the real-time transmission of data from the buoy, the ARGOS satellite system was selected. This system is also used for the transmission of XBT data collected during the VOS component of MFS. It was selected as the standard data transmission platform of MFS because (a) it is a system commonly used by the oceanographic community, (b) it has low energy requirements, (c) it has low operational costs
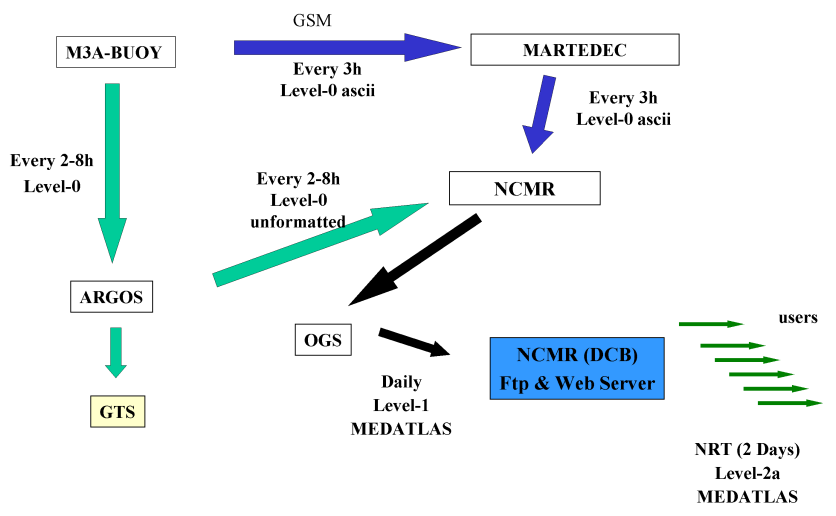

Fig. 3. External data flow of the M3A system.

and (d) it offers data dissemination through the GTS (Global Telecommunication System). An Argos IESM-PTT07 transmitter loads 12 encoded messages and relays them with a repetition period of $60 \mathrm{~s}$. The ARGOS satellite passage over the area is every $2-3 \mathrm{~h}$ with maximum gaps of $8 \mathrm{~h}$.

As a backup data transmission method the cellular telephony through the GSM network was selected. This system allows for a two-way communication between the operational center and the M3A buoy. The problem with the GSM transmission is the low performance during storms. Furthermore, this solution cannot be used at open-sea where such networks do not operate. The original M3A design included data transmission through Iridium or Globalstar, but these systems have not been successful up to now. The Orbcomm system, which is successfully used by the DOMEST project (Meinecke et al., 2000), and the Inmarsat-C system used by the POSEIDON project (Nittis et al., 2001) are possible alternatives. In the near future, the ODL system and the new generation of Argos are expected to provide new reliable solutions (Gamache and Fogel, 2000).

Before their transmission, data are converted in engineer units and encoded in standard Argos messages. The encoding procedure takes into account both requirements for high temporal resolution and high quality of data. Thus, data decimation uses the whole range of each sensor and almost its full accuracy (e.g. $0.01^{\circ} \mathrm{C}$ for temperature and $0.001 \mathrm{~S} / \mathrm{m}$ for conductivity). Upon reception by the ARGOS land station, data are automatically transferred by standard internet protocols (ftp) to the operational center of NCMR (National Center for Marine Research, Greece) that serves as the buoy data centre for MFS. Data are decoded and automatic safety controls are applied (position, battery level, functioning of sensors). This procedure allows for a fast reaction from the partners who are responsible for the safety of the system.

The second data transmission pathway through the GSM network delivers the data to MARTEDEC (Marine Technology Development Company SA, Greece) every $3 \mathrm{~h}$ and from there to NCMR through automatic ftp every $24 \mathrm{~h}$ (Fig. 3). All data are then transmitted to OGS (Italy) that has the overall responsibility for the quality control of data. Using automatic ftp, data are transferred back to NCMR 


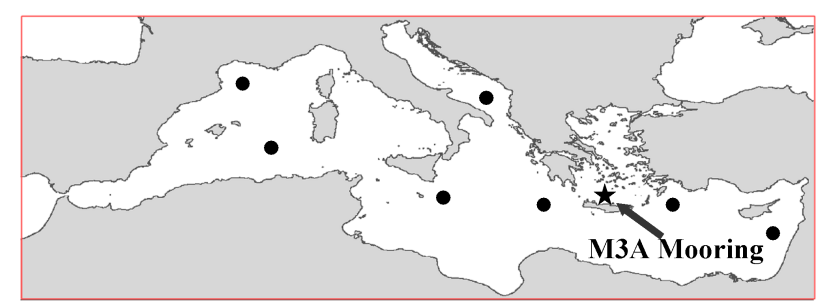

Fig. 4. Location of the M3A system during the pilot phase of MFS (star) and buoy locations during the second Phase of MFS according to the science plan (filled circles).

from where they are made available to users via web and ftp services (www.poseidon.ncmr.gr/m3a) in standard MEDATLAS format (www.ifremer.fr/sismer/program/medatlas/ $\mathrm{gb} / \mathrm{gb} /$ format.htm).

\subsection{Quality control of real-time data}

The quality control (QC) procedure carried out at OGS comprises a series of tests on the data in order to identify erroneous and anomalous values. Automatic QC consists of checks on individual or consecutive data points; these checks provide tests for instrument errors, physical limits of the data, rate of change, and stationarity of data. The checks considered in the procedure are the following:

- the values have to lie within the instrument's ranges;

- the values have to lie within the prefixed physical ranges;

- the values have to respect a rate of change in the time;

- the values cannot be constant over a time period relevant to the specific parameter.

Each QC check is performed in sequence and only if the previous one has been passed. Each of the automatic QC checks generates a flag when the check fails and the flag is ascribed to the data point failing the check. Data that pass all the checks are considered as "correct data". No editing of invalid data or replacement of missing data is performed. The overall procedure generates an output file in MEDATLAS format. The data quality control program is activated by an automatic procedure, running on a computer of OGS that daily:

- collects files of data coming from the M3A buoy via the ARGOS system or via GSM;

- prepares an input file for the data quality control program;

- activates the data quality control program providing the data for the last $24 \mathrm{~h}$;

- transmits the results (MEDATLAS file) to NCMR.

\section{Operation during the pilot phase of MFS}

According to the MFS science plan, the M3A system should be developed and tested during the first pilot phase of the project and should be expanded during the next two phases into an array that will cover the whole Mediterranean Sea. In Fig. 4, the positions of the M3A buoys during the first and second phases of MFS are presented. The Cretan Sea was selected as the area of operation of M3A during the pilot phase of MFS, for a variety of reasons. It is an area where open-sea conditions can be found in a relatively small distance from the coast. Furthermore, the Cretan Sea has been selected for the development of the 1D ecosystem model of MFS. The upper $100 \mathrm{~m}$ physical and biochemical data of M3A will be used for the initialization and calibration of this model. Another major advantage is the presence of the Institute of Marine Biology of Crete (IMBC) that facilitates the access to the system and guarantees a quick response in case of an accident.

The Cretan Sea has been extensively studied during the last decade in the framework of major international projects (POEM, CINCS, PELAGOS, MATER) and its characteristics are well documented (Theocharis et al., 1993, 1999b; Tselepides et al., 2000). The eastern Mediterranean has been characterised as one of the most oligotrophic areas of the world (Azov, 1986), with phosphorus being the liming nutrient (Krom et al., 1991; Thingstad and Rassoulzadegan, 1995). Among its main characteristics are the open-sea convection processes, responsible for the formation of the socalled Cretan Intermediate Water (Theocharis et al., 1999a).

\subsection{System deployment and periodic maintenance}

The deployment of the M3A system was carried out during January-March 2000. Lines 1 and 2 were deployed by R/V Aegaeo of NCMR on 30 January at a depth of $1030 \mathrm{~m}$, approximately $30 \mathrm{~nm} \mathrm{NW}$ of the city of Heraklion, Crete. Due to a problem with the exact depth of the sensors on line 2 (see also Fig. 6), the line was recovered on 9 February and re-deployed on 4 March 2000, together with line 3. Up until summer 2001, maintenance cruises were performed on 15 May 2000, 31 July 2000, 28 October 2000 and 19 April 2001. Additional visits at the buoy location were carried out for in situ repair of surface buoy electronics (March-May 2000) and for the second deployment of line 3 on 3 September 2000. Deployments of lines 2 and 3 and the maintenance cruises were carried our by R/V Filia of IMBC. Each maintenance expedition had a 3-4 day duration that included recovery and re-deployment of the system during the first and last day, respectively, and lab work at IMBC during the rest of the time. The typical activities during each visit included:

(a) at sea:

- Recovery of Line 2 and Line 3 (if applicable);

- Acquisition of water column samples at the exact depths of the M3A instruments. Preparation of 
samples for dissolved oxygen and nutrient analysis, filtering of samples for chlorophyll-a analysis;

- CTD cast down to $1500 \mathrm{~m}$ (using a SBE-25 CTD with auxiliary sensors for dissolved oxygen, fluorescence, transmittance, PAR);

- Checks/repairs on the surface buoy and recovery/cleaning of underwater instrument's cage attached to the buoy;

- External cleaning of all recovered devices (instruments, floats, ropes, etc.) using soapy water;

(b) in the Lab:

- Analysis of water samples for dissolved oxygen, chlorophyll-a and nutrients $\left(\mathrm{PO}_{4}, \mathrm{NO}_{3}, \mathrm{Si}\right)$;

- Downloading of data from the "Nireus" PC and the loggers of the individual instruments;

- Cleaning of instruments and sensors. For the defouling of instruments, standard methods proposed by the manufacturers were followed. The CTD probes (including the optical sensors) were flushed with soapy water and the tubes were cleaned using methanol. A Triton X-100 solution was used for cleaning of the conductivity sensors;

- Replacement of reagents in the nutrient analyzer;

- Replacement of batteries where needed, lubrication of o-rings, inspection of instrument's functionality;

- Re-assembly of line 2 and line 3 (if applicable).

\subsection{Calibration and delayed-mode quality control}

During each maintenance visit, the quality of M3A data was controlled against reference in situ measurements. Chlorophyll-a, dissolved oxygen and nutrients data were checked against the results of the laboratory analysis of water samples. The standard Winkler method (Carpenter, 1965) was used for dissolved oxygen, while a Turner 00-AU-10 fluorometer was used for the chlorophyll-a analysis. Fluorescence is converted to chlorophyll-a using the formula of Yentsch and Menzel (1963). Temperature, salinity, light attenuation and PAR data were compared against reference CTD measurements carried out by the SBE-25 of R/V Filia and the SBE-911 of R/V Aegaeo. Salinity measurements of the reference CTD casts were corrected against salinometer analysis of the water samples.

For the calibration procedure, both water samples and CTD casts were collected twice during each maintenance cruise, once during the recovery of the instruments and once during their deployment 2-3 days later. The first set of data was used for the estimation of fouling effects during the preceding measuring period, while the second data set was used for the re-calibration of sensors that had been cleaned during the above described maintenance procedures. Thus, this procedure corrects each time the data of the next measuring period.
From the values provided by the M3A instruments and the reference values, correction coefficients were estimated for the transfer functions that convert the sensor's output to engineering units. In all cases, correction coefficients were applied to the oxygen and chlorophyll-a measurements where the deviation between in situ and reference measurements was far above the sensor's accuracy $(0.5-1.2 \mathrm{ml} / 1$ for dissolved oxygen, $1.2-3.2 \mu \mathrm{g} / \mathrm{l}$ for chlorophyll-a). In fact, the initial values of chlorophyll-a estimated by the M3A fluorometers were one order of magnitude higher than the reference values $(0.6-3.2 \mu \mathrm{g} / \mathrm{l}$ instead of $0.05-0.5 \mu \mathrm{g} / \mathrm{l})$. This is probably related to the fact that the sensors had been calibrated by the manufacturer with different phytoplankton populations. Furthermore, the instrument's range $(0-75 \mu \mathrm{g} / \mathrm{l})$ is much larger than the typical ranges of the oligotrophic Cretan Sea.

It is interesting to note that for each oxygen or chlorophyll sensor, the correction coefficients estimated during the first 8 months of operation were each time the same (January, May and August 2000). This indicates that the sensors had a stable behavior during that period. The coefficients estimated during the following maintenance visits were different, indicating an important impact of the increased fouling during the summer period (see also Sect. 4).

The PAR sensors did not operate properly and thus, no correction was applied. For the light-attenuation sensors, there were no directly comparable measurements because the reference instruments were operating in different wavelengths. For the rest of the line- 2 sensors, the maximum deviation between reference and in situ measurements was $0.08^{\circ} \mathrm{C}$ for temperature, 0.05 for salinity and $0.2 \mu \mathrm{mol} / 1$ for nitrate, i.e. outside the accuracy limits of the sensors (Table 2). Nevertheless, such deviations are expected given the methodology that was followed ("quasi" simultaneous measurements at "quasi" the same depths at a distance of 100-500 m) and thus, no correction was applied to these data.

A more precise method for re-calibration of sensors would be to carry out simultaneous measurements using exactly the same water sample. This method requires the use of a mixing tank that will guarantee homogenous conditions during the measurement procedure. For better results, comparative measurements have to be taken at different concentrations, typical of the area of interest. This procedure is already used in the framework of the POSEIDON project with very promising results (Nittis et al., 2001) and will be applied in the next phase of MFS.

\subsection{System performance}

The main problem during the first year of pilot operation was caused by a false connection of the umbilical cable with the surface buoy. The first sign of the problem was the decreasing quality of data transmission from lines 1 and 2 through the umbilical. The problem appeared 3 weeks after the deployment of the system, but could not be traced until 5 months later when the same problem caused the detachment of the surface buoy from line 1 (end of June 2000). 


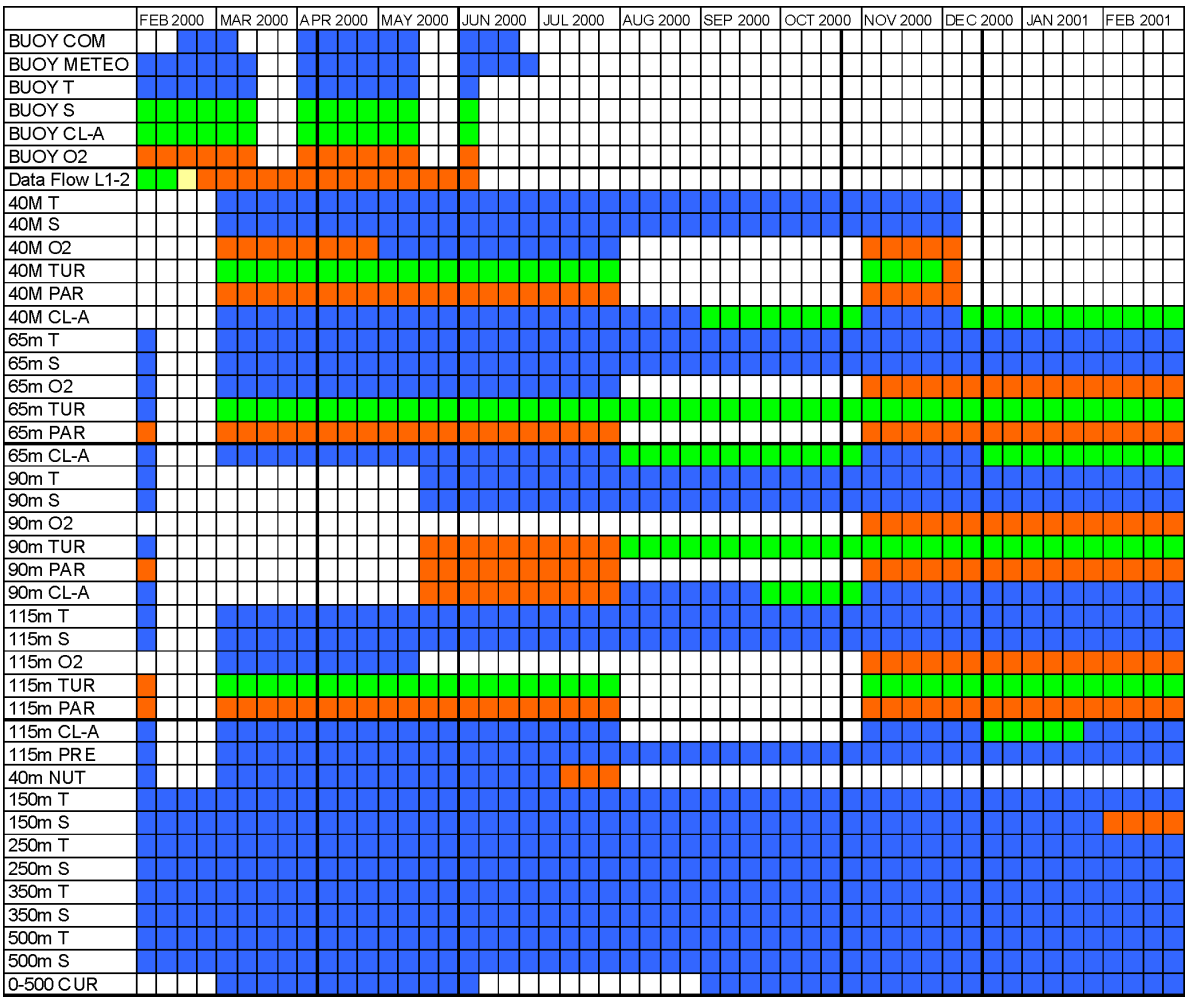

Fig. 5. Weekly performance of the various system components during the Pilot Phase of MFS. Colors indicate the quality of data, based on comparison against reference measurements. Blue: no need for calibration. Green: data were calibrated. Red: data could not be calibrated. White: no sensor during that period.
The buoy drifted for 3-4 days and was retrieved a week later (2 July 2000) from the northeast coasts of Crete, severely damaged. After the accident, the system continued its operation without real-time transmission and without surface data. Data from lines 2 and 3 were downloaded during the maintenance of the system, while data from line 1 were downloaded once (March 2001) when line 1 was retrieved. The analysis of those data followed the same quality control procedures that were defined for the real-time data and were made available in "delayed mode" to project partners.

During the operation of the surface buoy, data were transmitted mainly through the backup solution of GSM network. This was due to technical problems with the Argos antenna. During the short period of transmission through the Argos system, the successful retrieval of data was approximately $60 \%$. The main reason was the large volume of data that had to be transmitted through the system. Each cycle of measurement (every $3 \mathrm{~h}$ ) is encoded in 3 Argos messages. According to the transmission strategy that was selected, the last $3 \mathrm{cy}-$ cles of measurement are transmitted each time, i.e. 9 messages are repeated continuously for $3 \mathrm{~h}$. The average number of messages received by the satellite at each passage was much smaller and this resulted in a reduced success in data retrieval. These statistics are from approximately 5 months of operation of the Argos system. The backup solution of GSM provided an $80 \%$ overall successful data retrieval.

In Fig. 5, the overall performance of the M3A system during the pilot operation is presented. The table includes the performance of the individual sensors, as well as the above described functioning of internal and external com- munications. The white color indicates the absence of instruments/sensors that were at the lab or sent back to the factory for repair. Overall, problems were encountered with the sensors of light transmission and PAR. The light transmission sensors were found to be very sensitive to bio-fouling, even in the extremely oligotrophic conditions of the Cretan Sea. The PAR sensors did not operate properly due to a problem with their amplifier. Dissolved oxygen sensors gave reliable data after their re-calibration during the maintenance visits of the first six months, but an attempt for in situ repair was not successful and thus, data are missing after August 2000. All temperature and salinity sensors operated properly and there was no need for re-calibration during this period of operation.

\section{Presentation of selected time series}

Time series of pressure measurements from the sensors located at $150 \mathrm{~m}$ depth for line 1 (upper-most deep sensor) and $115 \mathrm{~m}$ depth for line 2 (deepest sensor for this line) are presented in Fig. 6. Remarkable vertical displacements of both mooring lines are observed, especially during the period September 2000 to January 2001. The most important event was on 15 December 2000 when a vertical displacement of $110 \mathrm{~m}$ was recorded on line 2 and $64 \mathrm{~m}$ on line 1 . All the events have a typical duration of 5-15 days and are associated with intensifications of the current field (Fig. 7). Smaller events observed during March-April 2000 are associated with higher frequency variability, possibly related to inertial waves. The maximum value of subsurface currents 


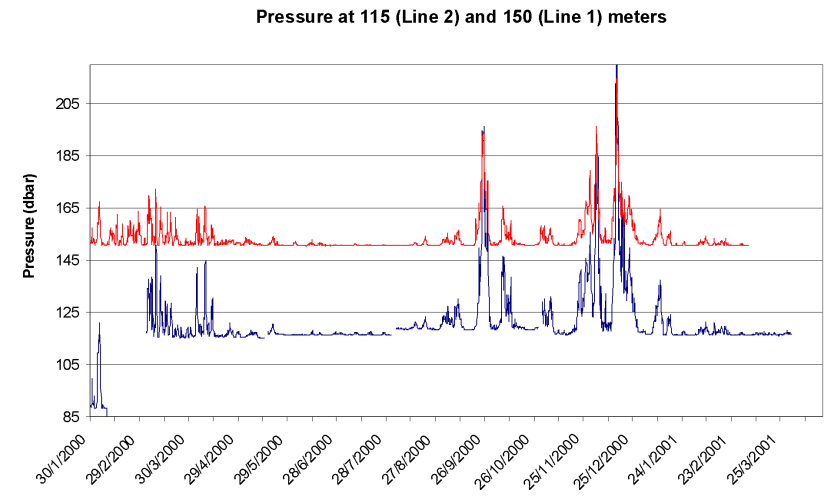

Fig. 6. Time series of pressure measurements for Line 1 (red) and Line 2 (blue).

$(50 \mathrm{~m})$ during the periods of maximum vertical displacements exceeds $50 \mathrm{~cm} / \mathrm{s}$, while the mean value is $15 \mathrm{~cm} / \mathrm{s}$. Similar values of currents have been considered during the design phase of the system in order to estimate the appropriate buoyancy for each mooring line. Values around $50 \mathrm{~cm} / \mathrm{s}$ were considered as extreme cases, but they turned out to be typical in this area, which is strongly influenced by energetic mesoscale structures (Theocharis et al., 1999b). These results indicate that the $450 \mathrm{~kg}$ buoyancy used for line 2 must be increased in the future in order to avoid such vertical displacements of the instruments that, among other factors, seem to influence the functioning of individual sensors (e.g. chlorophyll-a sensor, see Fig. 10). This is not valid for line 1, since during the period of extreme displacements, line 1 was not stabilized by the surface buoy and thus, its behavior cannot be considered typical.

The time series of temperature at different depths describe a complete annual cycle of the surface thermocline due to seasonal heating and cooling (Fig. 8). The onset of stratification starts at mid-April and the thermocline is at approximately $50 \mathrm{~m}$. Maximum subsurface temperature values are recorded at mid-October, followed by a gradual mixing that brings the thermocline into deeper layers, until it disappears in early January. Although the Cretan Sea is a well-known area for open-sea dense water formation processes (Theocharis et al., 1993), no deep mixing event was observed during these two winters. In fact, the weak stratification between 100 and $500 \mathrm{~m}$ remains very stable during the 15 months of observation. This weak stratification is typical for the Cretan Sea that has minimum temperatures above $13.9^{\circ} \mathrm{C}$, even at its deepest layers.

The vertical structure of salinity is more complicated since at least 3 different water masses can be detected (Figs. 8 and 9). The low salinity Modified Atlantic Water occupies the layer 40-100 m, the saline Cretan Intermediate Water in the layer 150-350 m, while the upper part of the Transitional Mediterranean Water is observed at $500 \mathrm{~m}$. Salinity variations in the upper layer are very strong (38.6-38.9), even in the synoptic time scale that is possibly under the influence of mesoscale eddy activity. During late October 2000 when the surface thermocline starts to weaken, the salinity values

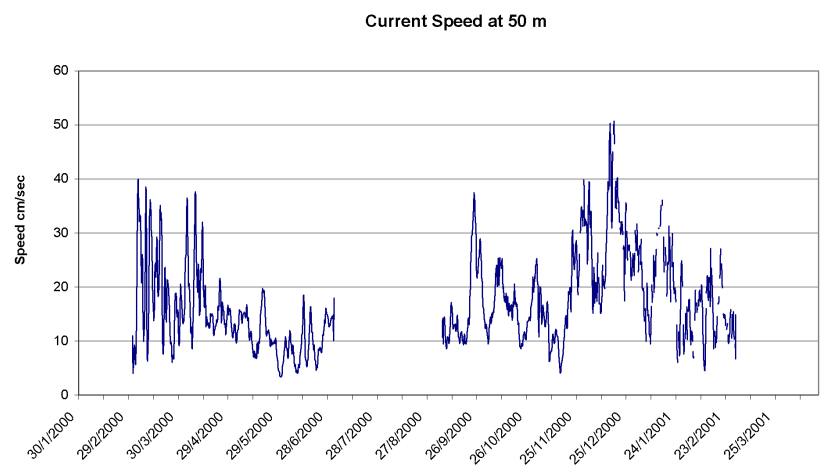

Fig. 7. Time series of current speed at $60 \mathrm{~m}$ depth. A low pass filter has been used to eliminate variability below $12 \mathrm{~h}$.

at $40 \mathrm{~m}$ increase significantly (39.1-39.3) under the influence of the surface saline waters formed during summer due to excess evaporation and warming. A more detailed description of water mass characteristics and their variability is given by Cardin et al. (2003).

Time series of chlorophyll-a (chl-a) concentrations in the upper $115 \mathrm{~m}$ are presented in Fig. 10. Data have been calibrated against water samples following the procedure described above. The chl-a profile given in Fig. $9 \mathrm{~b}$ has not been calibrated and thus, its absolute values should not be directly compared to the time series. It is mainly used to describe the vertical structure of chl-a, which is characterized by the sharp chlorophyll maximum at approximately $100 \mathrm{~m}$. Overall, the chl-a values are very low, less than $0.5 \mu \mathrm{g} / \mathrm{l}$ at the chl-a maximum layer and less than $0.1 \mu \mathrm{g} / \mathrm{l}$ below, in total agreement with previous findings for the area (Tselepides et al., 2000). During winter (February-March), chl-a concentrations are more uniform in the upper $100 \mathrm{~m}$ due to vertical mixing, while with the development of the thermocline, the chl-a maximum becomes more pronounced as the concentrations above $70 \mathrm{~m}$ decline significantly (see time series at $40 \mathrm{~m}$ and $65 \mathrm{~m}$ of Fig. 10). The effect of bio-fouling is mainly visible in two periods: between August and October 2000 at almost all depths and at the end of March 2001 for the $90 \mathrm{~m}$ sensor. At the end of these periods, the chl-a measurements deviate by more than $0.1 \mu \mathrm{g} / \mathrm{l}$ from the reference measurements (maximum deviation of $0.5 \mu \mathrm{g} / \mathrm{l}$ at the uppermost sensor for October 2000 and $0.4 \mu \mathrm{g} / \mathrm{l}$ for March 2001). It is interesting to note that although the chl-a concentrations are at the same range during the whole period, the increasing trends, probably related to bio-fouling, are more pronounced during summer and they start just after the redeployment of the sensors (beginning of August). The second increasing trend at end of March 2001 is rather expected due to the long residence of the instrument in the sea without maintenance (6 months). A second source of erroneous data in the chl-a time series is the vertical displacements of the mooring. Indeed, peaks of chl-a at $40 \mathrm{~m}$ during early October 2000 and at $115 \mathrm{~m}$ between December 2000 and January 2001 coincide with the strongest vertical displacements of mooring line 2. 
Temperature at $40,65,90,115,150,250,350$ and 500 meters

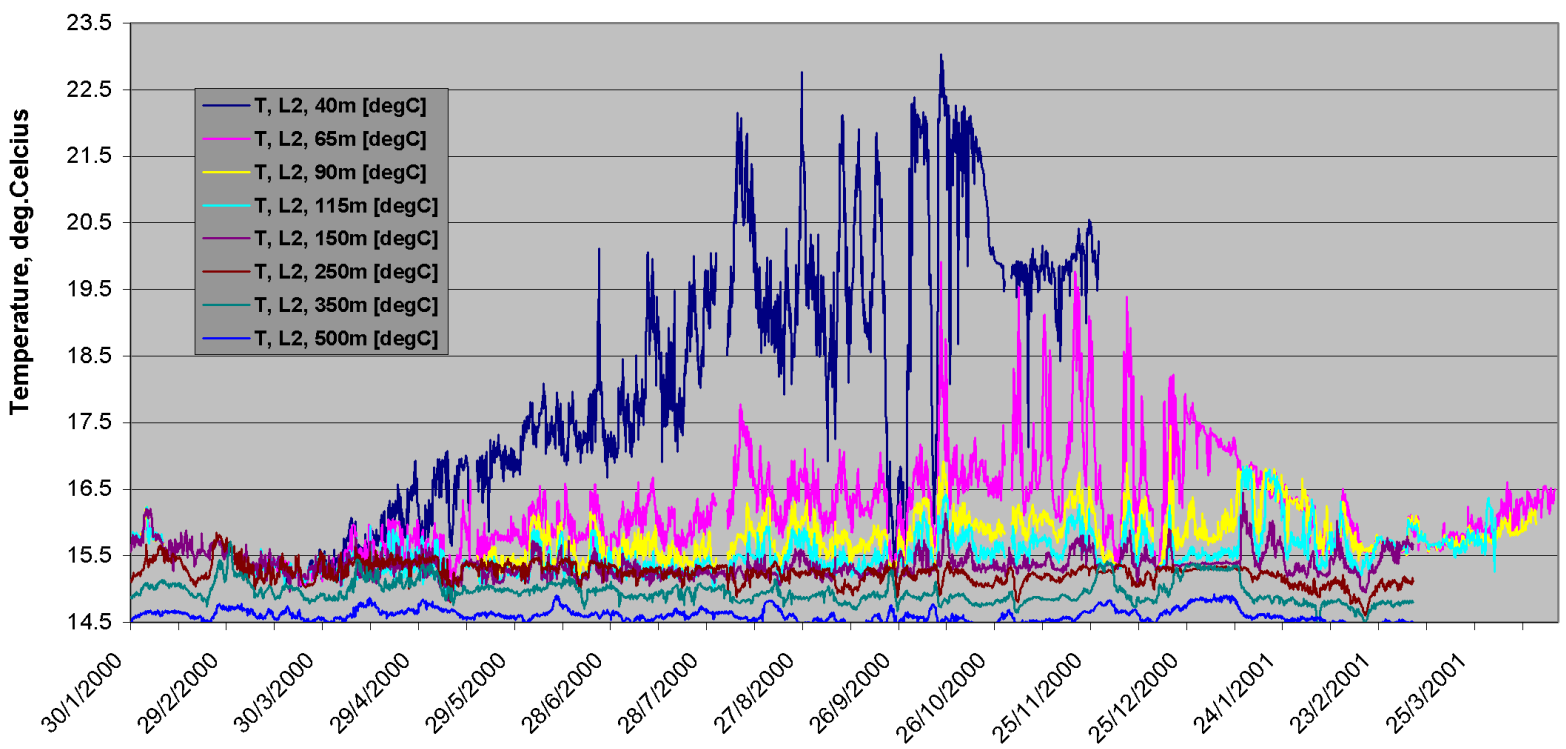

Salinity at $40,65,250$ and 500 metres

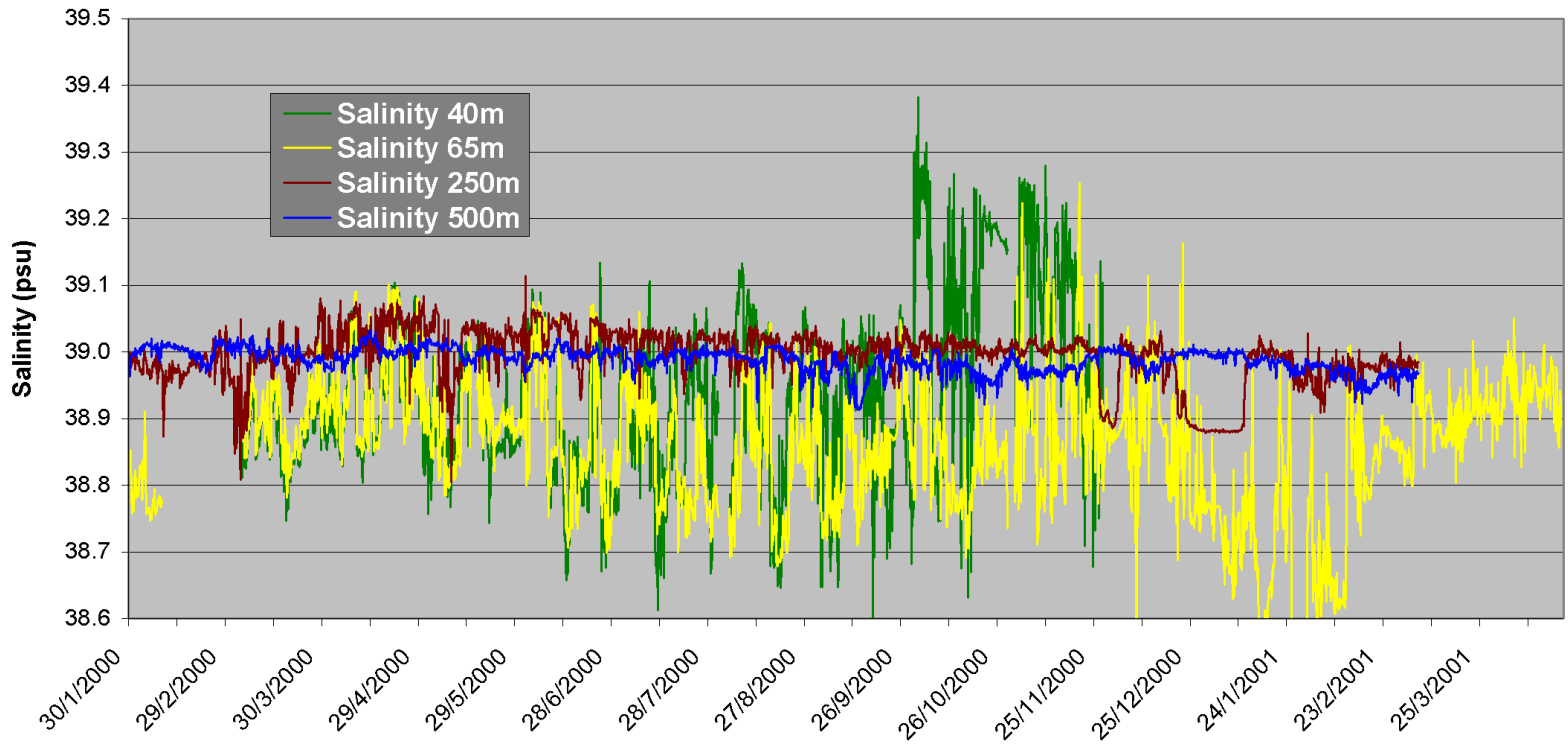

Fig. 8. Time series of temperature and salinity at 8 and 4 depths, respectively.

\section{Summary and conclusions}

The M3A system is one of the first efforts on a European level for multi-parametric real-time measurements of the upper and intermediate layers of the ocean. Similar efforts, such as the Bermuda Test-Bed Mooring and the HALE-ALOHA have provided not only very important data sets, but also the possibility to test and develop new instrumentation. The value of operational monitoring, even with less complicated systems, has been already demonstrated by the TAO array that provides the necessary data for the efficient forecast of El Niño many months in advance. Open ocean observing systems are now being developed for many of the world's oceans under the global perspective of GOOS. The prototype M3A system was developed and tested during the pilot phase of the Mediterranean Forecasting System. Its design takes into account the requirements for multi-parametric data necessary for the development of ecosystem models for the Mediterranean. The system integrates state-of-the-art sensors and communication techniques. Its modular design allows for independent handling of systems that have different maintenance requirements. In fact, during the pilot phase of MFS, the maintenance of M3A was carried out using a small research vessel, while a larger one was only used twice for the deployment and retrieval of all 3 mooring lines. In this way, the overall maintenance cost was significantly reduced. This 

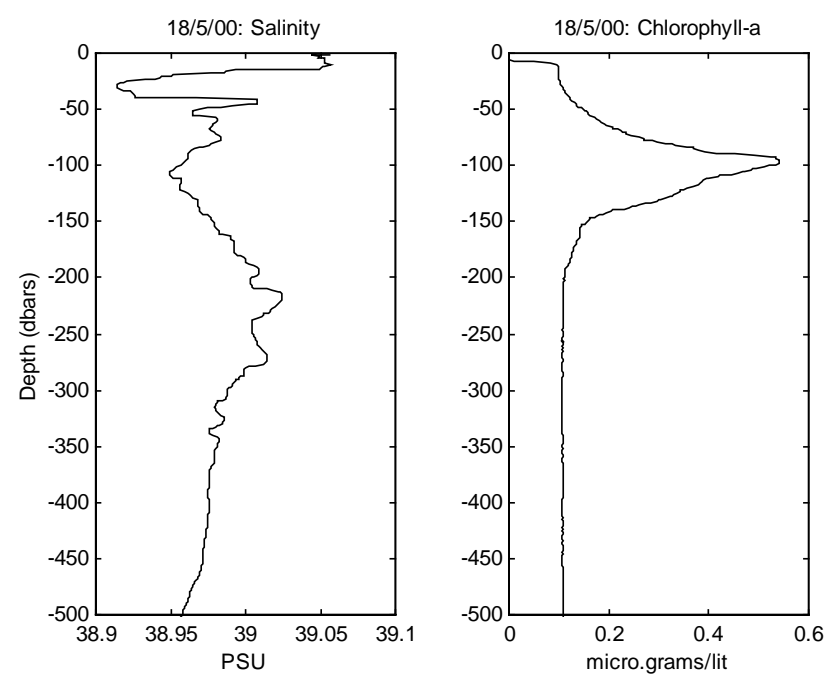

Fig. 9. Salinity and chlorophyll-a profiles at the M3A site on 18 May 2000. Data were collected during a regular maintenance cruise of R/V Filia using a SBE-25 CTD.

economic benefit is much larger than the additional cost of developing 3 instead of 1 mooring lines (cost of ropes, flotation and anchoring devices etc.). Another benefit is the quick response to system failures, since the access to small sized local vessels is usually much easier than the use of large research vessels. During the first 4 months of operation, line 2 was recovered twice for emergency repairs, apart from the regular maintenance visits. The system is expandable and can be enriched in the future with new sensors. For the next phase of MFS, the addition of a Phosphate analyzer in mooring line 2 is planned. The need for such a device was foreseen during the development phase of M3A, but no commercial system with the appropriate specifications (i.e. for the very low nutrient concentrations of the Mediterranean Sea) was available at that time. Overall, the use of distributed units that communicate through underwater acoustic links is a promising technology that is being tested in several new developments of operational systems (Frye et al., 1999; Meinecke et al., 2000).

The main problems during this pilot operation of the system were related to telecommunications and bio-fouling on optical sensors. A problem with the umbilical cable that transfers the data from both lines 1 and 2 to the surface buoy, disrupted the internal data flow of the system a few weeks after the deployment. For this reason, the hydro-acoustic communications could not be tested for a long period, especially during the summer when problems with the seasonal thermocline were expected. During the short period of operation of the Argos system, the data recovery was approximately $60 \%$ mainly due to the large volume of data that should have been transmitted. Transmission through the GSM network had a success rate of approximately $80 \%$, but the system is not applicable in the open sea and thus, cannot be used as the standard communication system of the M3A array. For the next phase of MFS, the Inmarsat-C satellite has already been selected for the standard transmission of data in real time. This system is being used on the 11 Seawatch buoys that operate in the Aegean Sea in the framework of the POSEIDON project and has proved to be very stable and reliable during the 3 years of continuous operation (Nittis et al., 2001). It has increased energy requirements compared to the Argos system but with a transmission frequency every $3 \mathrm{~h}$, it does not create any problems to the present energy budget of the surface buoy. Its operational costs are approximately increased by $30 \%$ compared to Argos, but it has the advantage of increased throughput and it offers two-way communication. The increased capacity of the next generation of Argos satellites and the development of new systems (e.g. Globalstar) are expected to provide additional reliable solutions in the near future.

Light transmittance sensors were found to be the most sensitive to bio-fouling, and the possibility of correcting the collected data is still under evaluation. Chlorophyll-a sensors (fluorometers) are also sensitive, but problems with biofouling were encountered only during certain periods of the year and at the end of long deployments. These sensors were also found to be sensitive to the strong vertical displacements of the mooring line during intensification of the current field. The results of these displacements are visible in all time series but their effect can, in general, be removed by using simple interpolation methods, since the exact displacement is recorded by the pressure sensors. Chlorophyll-a data cannot be corrected for this effect due to the unexpected response of the fluorescence sensors to these pressure variations. Overall, dissolved oxygen and chlorophyll-a sensors were able to provide reliable data after consistent re-calibration against in situ measurements during each maintenance cruise.

A preliminary analysis of data collected during the first year of operation shows the value of this data set for studies of physical-biological coupling in the open sea at various time scales and demonstrates the importance of continuous, multidisciplinary deep-sea monitoring. The area of study is found to be dominated by the presence of a strong dipole consisting of an anticyclonic gyre to the west and a cyclonic to the east of the mooring site. The interaction of these gyres influences both the current field and hydrological characteristics, at least in the upper $500 \mathrm{~m}$ of the water column. The bottom of the seasonal thermocline is at $50-70 \mathrm{~m}$ and thus, the signal of the annual cycle of heating and cooling is hardly detected below that depth.

The overall experience from the pilot deployment during 2000-2001 suggests that a continuous operation of the M3A system is feasible, but new developments that will improve certain characteristics of the system are required. The main problems encountered during the first year (communications, stability of mooring lines) can be solved with engineering improvements of the system. The effect of bio-fouling is probably the most important problem, especially for the sensors that use optical measurements. New methods and antifouling techniques, such as the generation of biocide chlorine compounds on tin oxide coating (Festy et al., 1998) or the use of UV pulses, are being developed in the framework of ongo- 


\section{Chlorophyll-a at 40, 65, 90 and 115 meters}

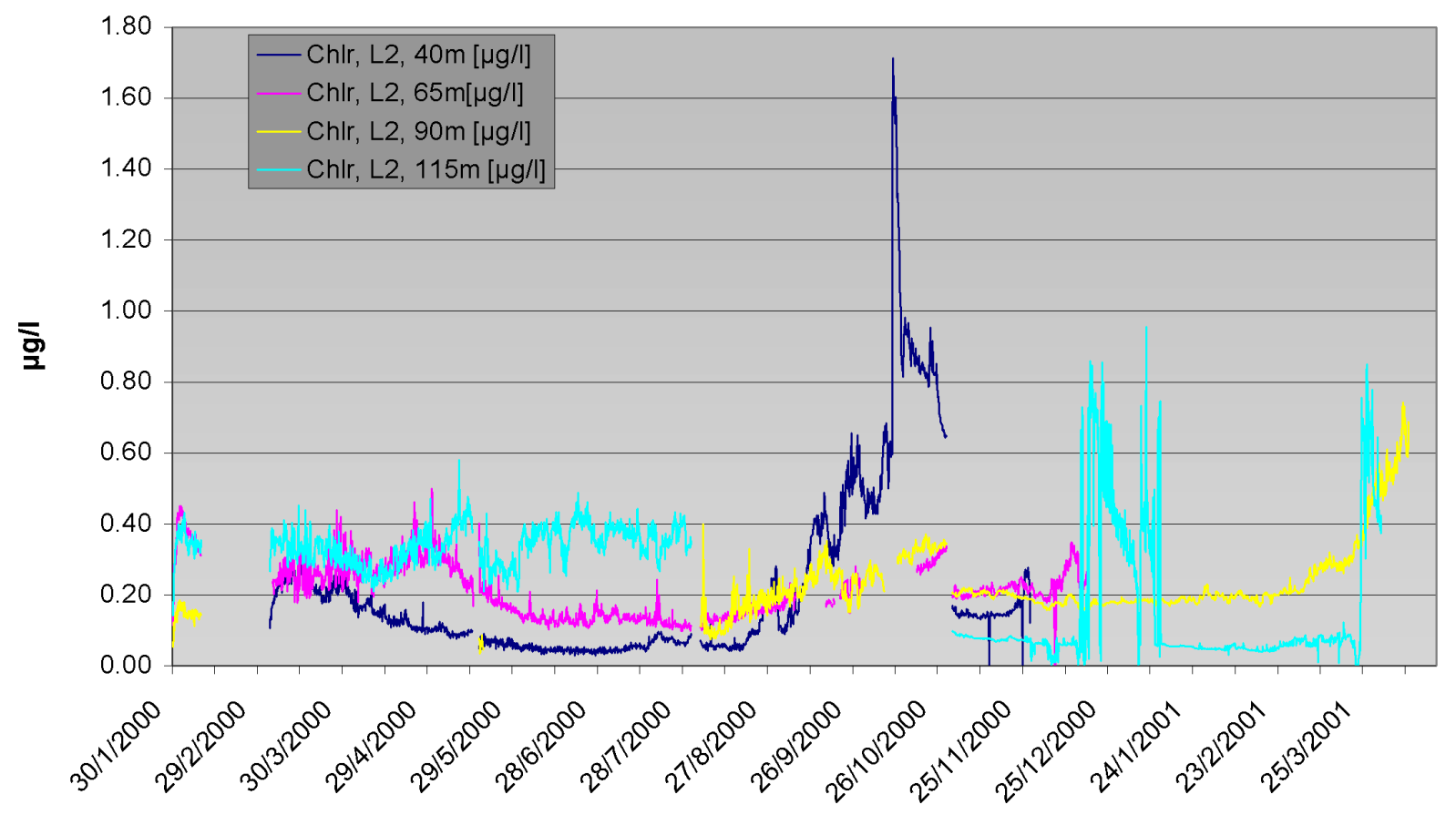

Fig. 10. Time series of chlorophyll-a at 40, 65, 90 and $115 \mathrm{~m}$ depth.

ing research projects and have started to give promising results. In the next phase of MFS, the copper shutters that have tested with very promising results at the BTM system, and the bromide-pumping technique (Strahle et al., 1998) proposed by certain manufacturers, will be tested. The applicability of other techniques, such as the tin oxide coating, will be explored. The performance of the different methods will be evaluated during a dedicated experiment using the instrumentation of M3A. Indeed, the M3A system could be used in the future as a test-bed where prototypes and new methodologies are evaluated.

The M3A data are being used by the MFS community for both process studies that improve our understanding of the Mediterranean Sea functioning (Cardin et al., 2003) and for the development of ecological models that simulate its ecosystem variability (Siddorn and Allen, 2003). Data assimilation methods are being developed by MFS partners in order to be able to use real-time M3A data into the MFS operational forecasting system. Furthermore, the M3A optical measurements will be used by the MFS remote sensing group to improve the analysis of space-born ocean color data. The major challenge for the next few years will be the deployment of additional M3A systems in the western and central Mediterranean Sea. This will be a main step towards a permanent, multi-parametric, open-ocean observing network that will support operational forecasting in the Mediterranean Sea.

Acknowledgement. The work was carried out in the framework of the Mediterranean Forecasting System - Pilot Project (MFS-PP).
We acknowledge the support of the European Commission MAST3 Program that financed the project under contract No MAS3-CT980171. The project was co-financed by the General Secretary of Research and Technology of the Hellenic Ministry of Development. The authors would like to thank Jacques Legrand and the anonymous reviewer for their comments that significantly improved this paper.

Topical Editor N. Pinardi thanks J. Legrand and another referee for their help in evaluating this paper.

\section{References}

Azov, Y.: Seasonal patterns of phytoplankton productivity and abundance in nearshore oligotrophic waters of the Levant Basin (Mediterranean), Journal of Plankton Research, 8, 41-53, 1986.

Butler, R., Chave, A. D., Coxm, C. S., Hesleym, C. E., Hildebrand, J. A., Lanzerotti, L. J., Purdy, G. M., and Schultz, A.: Scientific use of Submarine Telecommunications Cables, EOS Trans., AGU, 73, 97, 100-101, 1992.

Cardin, V., Gačić, M., Nittis, K., Kovacevic, V., and Perini, L.: Subinertial variability in the Cretan Sea from M3A buoy, Ann. Geophysicae, this issue, 2003.

Carpenter, J. H.: The accuracy of the Winkler method for the dissolved oxygen analysis, Limnology and Oceanology, 10, 135140, 1965.

Chiswell, S. M. and Lukas, R.: The Hawaii Ocean Time-series (HOT). EOS, Transactions of the American Geophysical Union 71, 1397, 1990.

Dickey, T.: Bermuda Testbed Mooring Program, Bull. Amer. Meteor. Soc., 76, 584, 1995. 
Dickey, T., Frye, D., Jannasch, H., Boyle, E., Manov, D., Sigurdson, D., McNeil, J., Stramska, M., Michaels, A., Nelson, N., Siegel, D., Chang, G., Wu, J., and Knap, A.: Initial results from the Bermuda Testbed Mooring program. Deep-Sea Research I, 45, 771-794, 1998.

Festy, D., LeBras, S., Clegg, M., Lacotte, N., Lehaitre, M., Menlove, R., and Sebastiao, P.: Biofilm prevention on optics by chlorine compound generation on tin oxide coating, OCEANS'98 IEEE Proceedings, ISBN 0-7803-5045-6, 733737, 1998.

Fischer, J. and Flemming, N. C.: Operational Oceanography: Data Requirements Survery. EuroGOOS publication No.12, SOC, Southampton, ISBN 0-904175-36-7, 1999.

Frye D., Heydt, K., v. d., Johnson, M., Maffei, A., Lerner, S., and Butman, B.: New technologies for coastal observatories, Sea Technology, 40(10), 29-35, 1999.

Gamache, K. A. and Fogel, P. E.: Oceanographic DATALINK, Sea Technology, 41(5), 23-31, 2000.

IOC: Towards Operational Oceanography: The Global Ocean Observing System, IOC/INF-1028, 1996.

Krom, M. D., Kress, N., and Brenner, S.: Phosphorus limitation of primary productivity in the eastern Mediterranean Sea, Limnology Oceanography, 36(3), 424-432, 1991.

McNeil, J. D., Jannasch, H. W., Dickey, T., McGillicuddy, D., Brzezinski, M., and Sakam, C. M.: New chemical, bio-optical, and physical observations of upper ocean response to the passage of a mesoscale eddy off Bermuda, J. Geophys. Res., 104, 15 537-15 548, 1999.

McPhaden, M. J., Busalacchi, A. J., Cheney, R., Donguy, J. R., Gage, K. S., Halpern, D., Ji, M., Julian, P., Meyers, G., Mitchum, G. T., Niiler, P. P., Picaut, J., Reynolds, R. W., Smith, N., and Takeuchi, K.: The Tropical Ocean-Global Atmosphere (TOGA) observing system: A decade of progress, J. Geophys. Res., 103, 14 169-14 240, 1998.

Meinecke, G., Ratmeyer, V., and Wefer, G.: DOMEST project: data access to deep sea, Sea Technology, 41(7), 25-29, 2000.

Nittis, K., Zervakis, V., Perivoliotis, L., Papadopoulos, A., and Chronis, G.: Operational Monitoring and Forecasting in the Aegean Sea: System Limitations and Forecasting Skill Evaluation, Marine Pollution Bulletin, 43/7-12, 154-163, 2001.

Philander, S. G. H.: A review of tropical ocean-atmosphere interactions, Tellus, 51A-B, 71-90, 1999.

Pinardi, N. and Flemming, E. (Eds): The Mediterranean Forecasting System, Science Plan, EuroGOOS Publication No 11, SOC, Southampton, ISBN 0-904175-35-9, 1998.
Provost, C. and du Chaffaut, M.: Yoyo Profiler: An Autonomous Multisensor, Sea Technology, 37 (10), 39-45, 1996.

Siddorn, J. R. and Allen, J. I.: Surface heat fluxes and ecosystem function in the Cretan Sea (Eastern Mediterranean): a modeling study, Ann. Geophysicae, this issue, 2003.

Strahle, W. J., Hotchkiss, F. S., and Martini, M. A.: Field results of antifouling techniques for optical instruments, OCEANS'98 IEEE Proceedings, ISBN 0-7803-5045-6, 723-727, 1998.

Thanos, I. and Pezirtzoglou, E.: Design and Construction of a Prototype Wave Directional Data Buoy, 5th Hellenic Symposium on Oceanography and Fisheries, April 1997, Kavala, Greece, NCMR, Vol I, and www.forthnet.gr/martedec, 1997.

Theocharis, A., Georgopoulos, D., Lascaratos, A., and Nittis, K.: Water masses and circulation in the central region of the Eastern Mediterranean: Eastern Ionian, South Aegean and Northwest Levantine, 1986-1987, Deep Sea Res. II, 40, 1121-1142, 1993.

Theocharis, A., Nittis, K., Kontoyiannis, H., Papageorgiou, E., and Balopoulos, E.: Climatic changes in the Aegean Sea influence the Eastern Mediterranean Thermohaline circulation, Geophys. Res. Lett., 26, 1617-1620, 1999a.

Theocharis, A., Balopoulos, E., Kioroglou, S., Kontoyiannis, H., and Iona, A.: A synthesis of the circulation and hydrography of the South Aegean Sea and the Straits of the Cretan Arc (March 1994 - January 1995), Progress in Oceanography, 44, 469-509, 1999 b.

Thingstad, T. F. and Rassoulzadegan, F.: Nutrient limitations, microbial food webs, and "biological C-pumps": suggested interactions in a P-limited Mediterranean, Marine Ecology Progress Series, 117, 299-306, 1995.

Tselepides, A., Zervakis, V., Polychronaki, T., Danovaro, R., and Chronis, G.: Distribution of nutrients and particulate organic matter in relation to the prevailing hydrographic features of the Cretan Sea (NE Mediterranean), Progress in Oceanography, 46, 113-142, 2000.

Tziavos, C. and Flemming, N.C. (Eds): The EuroGOOS Technology Plan Working Group Report, EuroGOOS Publication No 13, SOC, Southampton, ISBN 0-904175-37-5, 1999.

Woods, J. D., Dahlin, H., Droppert, L., Glass, M., Valerga, S., and Flemming, N. C.: The Plan for EuroGOOS, EuroGOOS publication No. 3, Southampton Oceanography Centre, Southampton, ISBN 0-904175-26-X, 1996.

Yentsch, C. S. and Menzel, D. W.: A method for the determination of phytoplankton chlorophyll and phaeophytin by fluorescence, Deep Sea Res., 10, 221-231, 1963. 